\title{
Electrochemical Degradation of Ethidium Bromide on Boron-doped Diamond Electrode Using Factorial Design Methodology
}

\author{
Fei Rong ${ }^{1,2,3, \text { a }}$, Zhen Ding ${ }^{4}$ and Chunyong Zhang ${ }^{3}$ \\ ${ }^{1}$ School of Biological Sciences and Medical Engineering, Southeast University, \\ Nanjing 210096, China; \\ ${ }^{2}$ Key Laboratory of Environmental Medicine Engineering of Ministry of Education, Southeast \\ University, Nanjing 210009, China; \\ ${ }^{3}$ Suzhou Key Laboratory of Environment and Biosafety, Suzhou 215123, China; \\ ${ }^{4}$ Jiangsu Centers for Disease Control and Prevention, Nanjing 210009, China; \\ arong@seu.edu.cn
}

Keywords: boron-doped diamond, electrochemical degradation, ethidium bromide, factorial design methodology

\begin{abstract}
Boron-doped diamond (BDD) electrochemical oxidation has been widely applied to the degradation of various organic pollutants, because BDD possesses unique physical and chemical properties as an ideal anode material. In this work, the degradation of ethidium bromide was studied by the electrochemical anodic oxidation through the use of BDD electrode. The effect of varoius operating parameters, such as treatment time, flow rate, applied current, initial concetration and concentration of supporting electrolyte, on treatment performance was evaluated by implementing a factorial design methodology. As a result, BDD exhibited high effeciency in the degradation of ethidium bromide. Among the five parameters involved, treatment time, applied current and initial concentration had considerable effects on the treatment performance. In additon, the results suggested that the factorial design methodology showed great applicability in the parameter optimization of BDD treatment technology.
\end{abstract}

\section{Introduction}

The recent use of a boron-doped diamond (BDD) electrode in anodic oxidation has shown that it possesses technologically important characteristics such as an inert surface with low adsorption properties, remarkable corrosion stability and an extremely wide potential window in aqueous media [1]. These properties make BDD electrode an ideal candidate for water treatment in the field of environmental electrochemistry [2].As an embedded fluorescent dye, ethidium bromide has been widely used for molecular biology research [3]. However, ethidium bromide is a potent mutagen which can embed in DNA bases, leading high carcinogenicity. For this reason, the elimination of Ethidium bromide from aqueous solution has received tremendous attention in recent years.

This paper studied the degradation of ethidium bromide on the BDD electrode through the electrochemical anodic oxidation. Five operating parameters, such as treatment time, flow rate, applied current, initial con and electrolyte concentration on treatment efficiency were discussed, and a factorial design methodology was employed estimate the statistically importance of the operating parameters.

\section{Experimental}

\subsection{Materials and Instruments.}

Ethidium bromide and $\mathrm{Na}_{2} \mathrm{SO}_{4}$ were all commercial compounds from Alfa Aesar and used without further purification. The water employed in this study was from AVP-2-35G-01 Water-system (Millipore, USA). BDD electrodes (boron-doped diamond thin film deposited on 
single crystal p-type Si wafer by MPCVD technology) of two sizes were supplied by Condias Corporation (Germany), with an effective surface area $77.44 \mathrm{~cm}^{2}$. The same size stainless steel plates were supplied by Linai Manufacturing Factory (Zhuhai, China). The gap between two electrodes was set as $10 \mathrm{~mm}$. The color removal rates during the anodic oxidation were monitored by measuring absorbance decrease of ethidium bromide (at wavelength of $480 \mathrm{~nm}$ ), using a UV-spectrophotometer (UV-2450, Shimatzu, Japan).

\subsection{Degradation Experiments.}

Degradation experiments were carried out in a batch one-compartment recirculation flow cell. The ethidium bromide solution and electrolyte were introduced in a reservoir and continuously circulated with a peristaltic pump at a flow rate of $250-500 \mathrm{~mL} / \mathrm{min}$, its temperature being maintained at $20^{\circ} \mathrm{C}$ by a cooling water bath. The processed volume was $200 \mathrm{ml}$, and three parallel experiments were performed for each sample and good reproducibility is obtained.

\subsection{Experimental Design and Analysis.}

In this study, we implemented factorial design methodology to evaluate the effect of the variables and their responses. A $2^{5}$ factorial design was employed to optimize of the electrochemical degradation of ethidium bromide on BDD anode (Table 1). Five test factors including treatment time $\left(\mathrm{X}_{1}, \mathrm{~min}\right)$, flow rate $\left(\mathrm{X}_{2}, \mathrm{~mL} / \mathrm{min}\right)$, applied current $\left(\mathrm{X}_{3}, \mathrm{~A}\right)$, initial concentration $\left(\mathrm{X}_{4}, \mathrm{mg} / \mathrm{L}\right)$ and electrolytes concentration $\left(\mathrm{X}_{5}, \mathrm{mmol} / \mathrm{L}\right)$ were applied to estimate the influence of the operating parameters on the treatment performance. And the factor levels (+ and -) represent high level and the low level, respectively. The effects of five test factors on degradation performance were analyzed by using the software package SPSS 17.0.

Table 1 Independent variables of the $2^{5}$ factorial design of experiment

\begin{tabular}{cccccc}
\hline Level & $\begin{array}{c}\mathrm{X}_{1} \\
(\mathrm{~min})\end{array}$ & $\begin{array}{c}\mathrm{X}_{2} \\
(\mathrm{~mL} / \mathrm{min})\end{array}$ & $\begin{array}{c}\mathrm{X}_{3} \\
(\mathrm{~A})\end{array}$ & $\begin{array}{c}\mathrm{X}_{4} \\
(\mathrm{mg} / \mathrm{L})\end{array}$ & $\begin{array}{c}\mathrm{X}_{5} \\
(\mathrm{mmol} / \mathrm{L})\end{array}$ \\
\hline- & 60 & 250 & 0.50 & 50 & 2.5 \\
+ & 120 & 500 & 1.00 & 100 & 10 \\
\hline
\end{tabular}

\section{Results and Discussions}

The design matrix of the experiments generated by the SPSS 17.0 is presented in Table 2 . The degradation efficiency of ethidium bromide was investigated by a full $2^{5}$ experimental set containing 32 experiments. Table 2 also collect the concentration of ethidium bromide and corresponding color removal rate after degradation.

Table 2 Design matrix of the $2^{5}$ factorial experimental design and results of color removal rate

\begin{tabular}{cccccccc}
\hline Entry & $\mathrm{X} 1$ & $\mathrm{X} 2$ & $\mathrm{X} 3$ & $\mathrm{X} 4$ & $\mathrm{X} 5$ & $\begin{array}{c}\mathrm{C}_{t} \\
(\mathrm{mg} / \mathrm{L})\end{array}$ & $\begin{array}{c}\text { Color removal rate } \\
(\%)\end{array}$ \\
\hline 1 & - & - & - & - & - & 23.2 & 53.6 \\
2 & + & - & - & - & - & 13.9 & 72.2 \\
3 & - & + & - & - & - & 21.6 & 56.7 \\
4 & + & + & - & - & - & 12.3 & 75.3 \\
5 & - & - & + & - & - & 15.3 & 69.3 \\
6 & + & - & + & - & - & 7.1 & 85.9 \\
7 & - & + & + & - & - & 13.7 & 72.6 \\
8 & + & + & + & - & - & 5.1 & 89.7 \\
9 & - & - & - & + & - & 47.7 & 52.3 \\
10 & + & - & - & + & - & 28.3 & 71.7 \\
11 & - & + & - & + & - & 44.1 & 55.9 \\
12 & + & + & - & + & - & 24.2 & 75.8 \\
13 & - & - & + & + & - & 47 & 53.0 \\
\hline
\end{tabular}




\begin{tabular}{llllllll}
\hline 14 & + & - & + & + & - & 12.4 & 87.6 \\
15 & - & + & + & + & - & 33.1 & 66.9 \\
16 & + & + & + & + & - & 13.8 & 86.2 \\
17 & - & - & - & - & + & 23.4 & 53.3 \\
18 & + & - & - & - & + & 14.5 & 71.0 \\
19 & - & + & - & - & + & 20.6 & 58.8 \\
20 & + & + & - & - & + & 12.5 & 74.9 \\
21 & - & - & + & - & + & 16.8 & 66.3 \\
22 & + & - & + & - & + & 6.2 & 87.7 \\
23 & - & + & + & - & + & 14.8 & 70.4 \\
24 & + & + & + & - & + & 4.9 & 90.1 \\
25 & - & - & - & + & + & 41.2 & 58.8 \\
26 & + & - & - & + & + & 22.7 & 77.3 \\
27 & - & + & - & + & + & 37.8 & 62.2 \\
28 & + & + & - & + & + & 20.3 & 79.7 \\
29 & - & - & + & + & + & 28.6 & 71.4 \\
30 & + & - & + & + & + & 9.8 & 90.2 \\
31 & - & + & + & + & + & 25.4 & 74.6 \\
32 & + & + & + & + & + & 7.9 & 92.1 \\
\hline
\end{tabular}

The average effect, as well as the main and interaction effects were evaluated by using SPSS 17.0 using color removal amount of ethidium bromide as response factor. The results obtained in terms of response factor were presented in Table 3, in which PSE (pseudo-standard error), ME (a margin of error) and SME (a simultaneous margin of error) were calculated by Lenth's method [4].

Table 3 Average and main effects of the independent variables and their two and higher order interactions of the $2^{5}$ factorial design on the response factor

\begin{tabular}{|c|c|c|c|c|c|c|c|}
\hline Effect & $\begin{array}{l}\text { Effect } \\
\text { value }\end{array}$ & Effect & $\begin{array}{l}\text { Effect } \\
\text { value }\end{array}$ & Effect & $\begin{array}{l}\text { Effect } \\
\text { value }\end{array}$ & Effect & $\begin{array}{l}\text { Effect } \\
\text { value }\end{array}$ \\
\hline $\begin{array}{l}\text { Main } \\
\text { effect }\end{array}$ & & $\begin{array}{l}\text { Two-factor } \\
\text { interactions }\end{array}$ & & $\begin{array}{l}\text { Three-factor } \\
\text { interactions }\end{array}$ & & $\begin{array}{l}\text { Four-factor } \\
\text { interactions }\end{array}$ & \\
\hline $\mathrm{X}_{1}$ & 14.90 & $\mathrm{X}_{1} \cdot \mathrm{X}_{2}$ & -1.14 & $\mathrm{X}_{1} \cdot \mathrm{X}_{2} \cdot \mathrm{X}_{3}$ & -0.98 & $\mathrm{X}_{1} \cdot \mathrm{X}_{2} \cdot \mathrm{X}_{3} \cdot \mathrm{X}_{4}$ & -1.04 \\
\hline $\mathrm{X}_{2}$ & 2.88 & $\mathrm{X}_{1} \cdot \mathrm{X}_{3}$ & 1.04 & $\mathrm{X}_{1} \cdot \mathrm{X}_{2} \cdot \mathrm{X}_{4}$ & -1.00 & $\mathrm{X}_{1} \cdot \mathrm{X}_{2} \cdot \mathrm{X}_{3} \cdot \mathrm{X}_{5}$ & 0.95 \\
\hline $\mathrm{X}_{3}$ & 9.15 & $\mathrm{X}_{1} \cdot \mathrm{X}_{4}$ & 5.79 & $X_{1} \cdot X_{2} \cdot X_{5}$ & 0.66 & $\mathrm{X}_{1} \cdot \mathrm{X}_{2} \cdot \mathrm{X}_{4} \cdot \mathrm{X}_{5}$ & 0.90 \\
\hline $\mathrm{X}_{4}$ & 36.35 & $\mathrm{X}_{1} \cdot \mathrm{X}_{5}$ & -1.18 & $\mathrm{X}_{1} \cdot \mathrm{X}_{3} \cdot \mathrm{X}_{4}$ & 0.83 & $\mathrm{X}_{1} \cdot \mathrm{X}_{3} \cdot \mathrm{X}_{4} \cdot \mathrm{X}_{5}$ & -1.23 \\
\hline \multirow[t]{7}{*}{$\mathrm{X}_{5}$} & 3.36 & $\mathrm{X}_{2} \cdot \mathrm{X}_{3}$ & 0.19 & $\mathrm{X}_{1} \cdot \mathrm{X}_{3} \cdot \mathrm{X}_{5}$ & -0.56 & $\mathrm{X}_{2} \cdot \mathrm{X}_{3} \cdot \mathrm{X}_{4} \cdot \mathrm{X}_{5}$ & -0.23 \\
\hline & & $\mathrm{X}_{2} \cdot \mathrm{X}_{4}$ & 1.01 & $\mathrm{X}_{1} \cdot \mathrm{X}_{4} \cdot \mathrm{X}_{5}$ & -1.44 & Five-factor & \\
\hline & & $\mathrm{X}_{2} \cdot \mathrm{X}_{5}$ & -0.50 & $X_{2} \cdot X_{3} \cdot X_{4}$ & 0.33 & interactions & \\
\hline & & $X_{3} \cdot X_{4}$ & 1.89 & $X_{2} \cdot X_{3} \cdot X_{5}$ & -0.46 & $\mathrm{X}_{1} \cdot \mathrm{X}_{2} \cdot \mathrm{X}_{3} \cdot \mathrm{X}_{4} \cdot \mathrm{X}_{5}$ & 0.99 \\
\hline & & $\mathrm{X}_{3} \cdot \mathrm{X}_{5}$ & 0.68 & $\mathrm{X}_{2} \cdot \mathrm{X}_{4} \cdot \mathrm{X}_{5}$ & -0.66 & Lenth’s PSE & 1.47 \\
\hline & & $\mathrm{X}_{4} \cdot \mathrm{X}_{5}$ & 3.65 & $\mathrm{X}_{3} \cdot \mathrm{X}_{4} \cdot \mathrm{X}_{5}$ & 0.86 & ME & 3.53 \\
\hline & & & & & & SME & 5.77 \\
\hline
\end{tabular}

Fig. 1 presents the normal probability plot for each effect value by means of the results from Table 3. As shown in Figure 1, initial concentration $\left(\mathrm{X}_{4}\right)$, treatment time $\left(\mathrm{X}_{1}\right)$, applied current $\left(\mathrm{X}_{3}\right)$ and test factor $\mathrm{X}_{1} \mathrm{X}_{4}$ had great influence to the color removal rate. Moreover, the effect of test factor $\mathrm{X}_{4} \cdot \mathrm{X}_{5}$ on color removal should be considered to a certain extent. All other effects, such as flow rate $\left(\mathrm{X}_{2}\right)$ and Electrolyte concentration $\left(\mathrm{X}_{5}\right)$, distributed near a straight line, which suggested very small effect on color removal. 

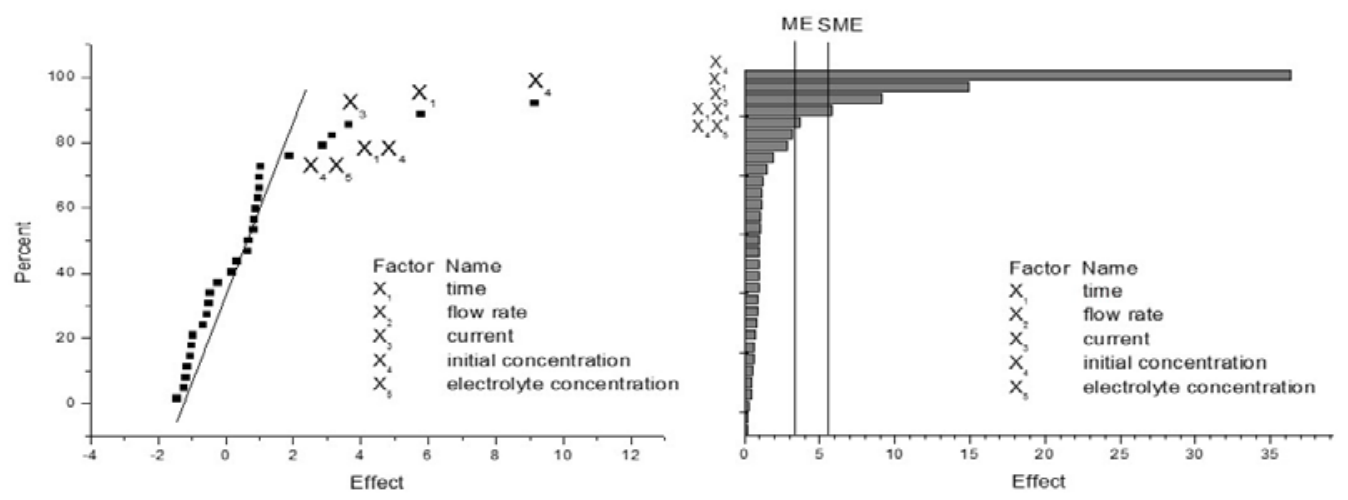

Fig. 1 Normal probability plot of the effects for Fig. 2 Pareto chart of the effects for color removal color removal for the full $2^{5}$ factorial design

Pareto chart was usually used to confirm the statistical importance of estimated effects. The Pareto chart of the effects for the color removal as well as the decision lines for ME and SME was shown in Fig. 2. As can be seen from the bar chart, the values of four effects $\left(\mathrm{X}_{1}, \mathrm{X}_{3}, \mathrm{X}_{4}\right.$ and $\left.\mathrm{X}_{1} \cdot \mathrm{X}_{4}\right)$ were larger than the SME, which suggested that the treatment time, applied current, initial concentration and $\mathrm{X}_{1} \cdot \mathrm{X}_{4}$ played an important role in the electrochemical degradation. The value of $\mathrm{X}_{4} \cdot \mathrm{X}_{5}$ was between the ME and the SME, which demonstrated that it should be paid attention in some circumstance. The values of all other effects were lower than the ME, revealing a negligible effect on color removal. These results were well consistent with those deduced from Fig. 1.

\section{Summary}

In this paper, we reported a detailed discussion to the electrochemical degradation of ethidium bromide on BDD electrode, and the optimization of experiment procedures was conducted by using factorial design methodology. The effects of five test factors including treatment time, flow rate, applied current, initial concentration and electrolytes concentration on treatment performance were investigated. The results showed that the effects of the various operating parameters on treatment efficiency were remarkably different, and the treatment performances were vastly influenced by the factors of treatment time, applied current, initial concentration and $\mathrm{X}_{1} \cdot \mathrm{X}_{4}$. Therefore, the factorial design methodology of the various factors is be of great useful to the optimization of operating parameters.

\section{Acknowledgement}

The work was financially supported by Natural Science Foundation of China (GN: 81202250), Sci-tech Development Program of Suzhou (GN: SYG201445), Social Developing Program of Jiangsu Province (BE2011797), Open Research Fund Program of Key Laboratory of Environmental Medicine and Engineering of Ministry of Education (Southeast University, No.2010EME004).

\section{References}

[1]. Fujishima, A., Tada, N., Rao, D.A., et al. 2000. $\mathrm{TiO}_{2}$ Photocatalysts and Diamond Electrodes. Electrochim. Acta. (2000)No.45, p.4683-4690.

[2]. Muff, J., Jepsen, H., Sogaard, E. Bench-scale study of electrochemical oxidation for 0n-Site treatment of polluted groundwater. J. Environ. Eng. (2012) No. 138, p.915-933.

[3]. Information on: baike.baidu.com

[4]. Lenth, R. V. Quick and easy analysis of unreplicated factorials. Technometrics. (2008)No.31, p.469-473. 